\title{
Antimicrobial activity as a potential factor influencing the predominance of Bacillus subtilis within the constitutive microflora of a whey reverse osmosis membrane biofilm
}

Pratishtha Verma and Sanjeev Anand* ()

Midwest Dairy Foods Research Center, Dairy and Food Science Department, South Dakota State University, Brookings 57007

\begin{abstract}
Current cleaning and sanitation protocols may not be adequately effective in cleaning separation membranes and can result in the formation of resilient multispecies biofilms. The matured biofilms may result in a bacterial predominance with resilient strains on membranes with a prolonged use. In our previous study, we isolated organisms such as Bacillus subtilis, Bacillus licheniformis, Exiguobacterium aurantiacum, and Acinetobacter radioresistens from an 18-mo-old reverse osmosis membrane. The competitive exclusion studies revealed the predominance of $B$. subtilis within the membrane biofilm microflora. This study investigated the antimicrobial activity of the B. subtilis isolate as a potential cause of its predominance. The culture isolate was propagated in tryptic soy broth at $37^{\circ} \mathrm{C}$, and microfiltered to prepare cell-free extracts (CFE) at 8-, 10-, 12-, 14-, 16-, and 18-h intervals. The CFE were freeze-dried and suspended in minimum quantities of HPLC-grade water to prepare concentrated solutions. The antimicrobial activities of CFE were tested using the agar-well assay against the biofilm constitutive microflora. The experiments were conducted in triplicates and means were compared for significant differences using a general linear mixed model procedure. The results indicated the highest antimicrobial activity of 12-h CFE of B. subtilis against other constitutive microflora such as Exiguobacterium sp., E. auranticum, and A. radioresistens, with average inhibition zone sizes of 16.5 $\pm 0.00,16.25 \pm 0.66$, and $20.6 \pm 0.00 \mathrm{~mm}$, respectively. Upon treatment with proteinase $\mathrm{K}$, the CFE completely lost its antimicrobial activity, establishing it to be a proteinaceous compound. The AA profiling revealed the total crude protein in CFE to be $51 \%$ (wt/wt), with its major constituent as glutamic acid (11.30\% wt/wt). The freeze-dried CFE was thermally stable on exposure to the common temperature used for sanitizer applica-
\end{abstract}

Received March 22, 2020.

Accepted June 30, 2020.

*Corresponding author: sanjeev.anand@sdstate.edu tions $\left(23.8^{\circ} \mathrm{C}\right.$ for 5 and $\left.10 \mathrm{~min}\right)$ and over a $\mathrm{pH}$ range of 3.0 to 6.3 . The study helped us understand the role of the antimicrobial compound produced by B. subtilis as a potential cause of its predominance within the biofilm constitutive microflora.

Key words: biofilms, antimicrobial activity, predominance

\section{INTRODUCTION}

Several microorganisms tend to attach to the surface of filtration membranes and initiate colonization on the membrane surfaces (Anand et al., 2012). These colonies are also referred to as biofilms and consist of complex communities of microorganisms (Tait and Sutherland, 2002). These biofilms are hard to clean and have been reported to develop resistance to chemical processes when compared with their planktonic counterparts (Anand et al., 2014; Sayem et al., 2018; Unlu et al., 2018 ); this proves the cleaning and sanitization protocols to be ineffective, which results in the formation of resilient multispecies biofilms (Stoodley et al., 2002). When the biofilm microflora is subjected to disinfectants, the sensitive cells die, but resilient cells develop bacterial resistance against the chemical cleaners. This emphasizes the need to discover new eco-friendly natural antimicrobials for effective membrane cleaning and prevention of resistance development in the biofilm constitutive microflora. Our previous study on the resilient biofilm microflora reported resistance developing by selective isolates over prolonged use of membranes and their potential to gain predominance in the biofilm matrix (Anand and Singh, 2013; Gupta and Anand, 2018). The microbial resistance development leads to an efficiency reduction of almost all antimicrobial treatments. In addition, these strains rapidly generate additional resistance to new synthetic derivatives, as they have already acquired resistance to the parent agents (Sumi et al., 2015). This has encouraged researchers to focus on novel alternative strategies to control biofilm formation. In recent years, various approaches have been followed to eliminate biofilm development. Some 
studies have aimed to prevent the adhesion of microbes, and others have focused on inhibition of biofilms by killing the microorganisms attached to the contact surfaces (Thallinger et al., 2013; Unlu et al., 2018). The emergence of predominance could be associated with several factors including competition for the nutrients, faster growing rate, production of bacteriocins, secretion of broad and narrow spectrum toxins with coupled privatized antitoxin, and the release of certain matrix protein-like TasA, which provides structural integrity to biofilms. (Van Merode et al., 2007; Nadell et al., 2016; Yannarell et al., 2019). Natural antimicrobial peptides have the potential to eliminate the issue of ineffectiveness due to resistance development (Lisboa et al., 2006; Rotem and Mor, 2009). These substances mainly form channels or interact directly with the cell membrane and cause membrane disruption, leading to bacterial cell death (Shelburne et al., 2007; Sumi et al., 2015). Thus, this provides an edge to such substances to prevent biofilm formation over the conventional chemical cleaners. Studies have reported the release of antimicrobial substances by the genus Bacillus (Lisboa et al., 2006; Abriouel et al., 2011). These substances have gained attention due to their broad-spectrum inhibition and antagonistic effect against fungi, bacteria, and insects (Hammami et al., 2009). Studies have supported that such bacteriocins inhibit the growth of closely related species (Lisboa et al., 2006; Nadell et al., 2016), and express self-inhibition of the producing strain at a certain level of bacteriocin production (Balakrishnan et al., 2002; Altuntas, 2013). This study is one such attempt where we screened the predominant Bacillus subtilis isolate for natural antimicrobials that might have inhibited the growth of the other constitutive microflora of an 18-mo-old reverse osmosis (RO) membrane biofilm. The B. subtilis strain used in this study was originally isolated in the previous study conducted in our laboratory, along with other constitutive microflora (Verma et al., 2020). The objective of this study was to screen the antimicrobial activity of $B . s u b$ tilis, an isolate of the biofilm microflora, and to establish its possible role with emergence of predominance.

\section{MATERIALS AND METHODS}

\section{Bacterial Isolates, Growth Conditions, and Culture Media}

Bacillus subtilis, used in this study, was originally isolated during a previous study conducted in our laboratory using an 18-mo-old RO membrane obtained from a whey processing commercial plant (Verma et al., 2020). The B. subtilis strain was observed to be the predominant culturable bacteria within the biofilm formed on the retentate side of the used RO membrane, which operated over $18 \mathrm{mo}$ at approximately 15 to $19^{\circ} \mathrm{C}$. The membrane was cleaned before shipping for analysis and the microflora was isolated with culturing techniques after neutralizing any chemical residues using Letheen Broth (Puritan ESK sampling kits with pre-filled Letheen broth, Guilford, ME).

The other isolates obtained from the biofilm microflora of that membrane that were used in this study included Exiguobacterium sp., Bacillus licheniformis, Bacillus sp., Exiguobacterium aurantiacum, and Acinetobacter radioresistens. All of these isolates were stored in cryovials at $-75^{\circ} \mathrm{C}$ in a deep freezer (Nuarie, Plymouth, MN). The culture isolates were activated in tryptic soy broth (TSB; Bacto, Rockville, MD) by inoculating a single bead from the stock cryovials and incubating them at $37^{\circ} \mathrm{C}$ for overnight. Micrococcus luteus (ATCC 10240) was used as the indicator strain due to its high sensitivity (Oscáriz et al., 1999). We used it for the initial screening for antimicrobial activity of the cell-free extract (CFE) of B. subtilis with an agar-well assay. The culture was grown using nutrient broth (Difco, Sparks, MD) for $72 \mathrm{~h}$ at $30^{\circ} \mathrm{C}$.

\section{Antimicrobial Activity of the B. subtilis CFE}

To determine the antimicrobial activity of CFE of $B$. subtilis, 3 major sets of experiments were conducted, which have been depicted in the form of a flowchart (Figure 1) and described below.

Preparation of the Freeze-Dried CFE. The predominant $B$. subtilis isolate from the RO membrane biofilm microflora was selected for the antimicrobial study. To evaluate the release of an antimicrobial substance, $1 \mathrm{~mL}$ of activated culture of $B$. subtilis was inoculated into $100 \mathrm{~mL}$ of TSB and incubated for $12 \mathrm{~h}$ at $37^{\circ} \mathrm{C}$. The culture growth was centrifuged at $6,000 \times$ $g$ at $4^{\circ} \mathrm{C}$ for 15 min (Camargo et al., 2003) and microfiltered using a $0.22-\mu \mathrm{m}$ Millipore filter (Stericup quick release, EMD Millipore Corporation, Billerica, MA) to prepare the $\mathrm{CFE}$. The $\mathrm{CFE}$ was kept at $-75^{\circ} \mathrm{C}$ in a deep freezer overnight and subsequently freeze-dried (Labconco Corporation, Kansas City, MO) by setting up the freeze-drier at 0.498 mbar vacuum pressure with the collector temperature at $-50 \pm 2{ }^{\circ} \mathrm{C}$.

Screening for the Antimicrobial Activity of Freeze-Dried CFE Against the Test Strain M. luteus. The antimicrobial activity of the CFE was screened using the in vitro agar-well assay method described by Balouiri et al. (2016). The freeze-dried CFE of B. subtilis, containing $51 \%$ protein content, was reconstituted by adding $762 \mathrm{mg}$ of freeze-dried CFE in $650 \mu \mathrm{L}$ of sterile HPLC-grade water. Petri plates were poured with $13 \mathrm{~mL}$ of the tryptic soy agar, pre- 


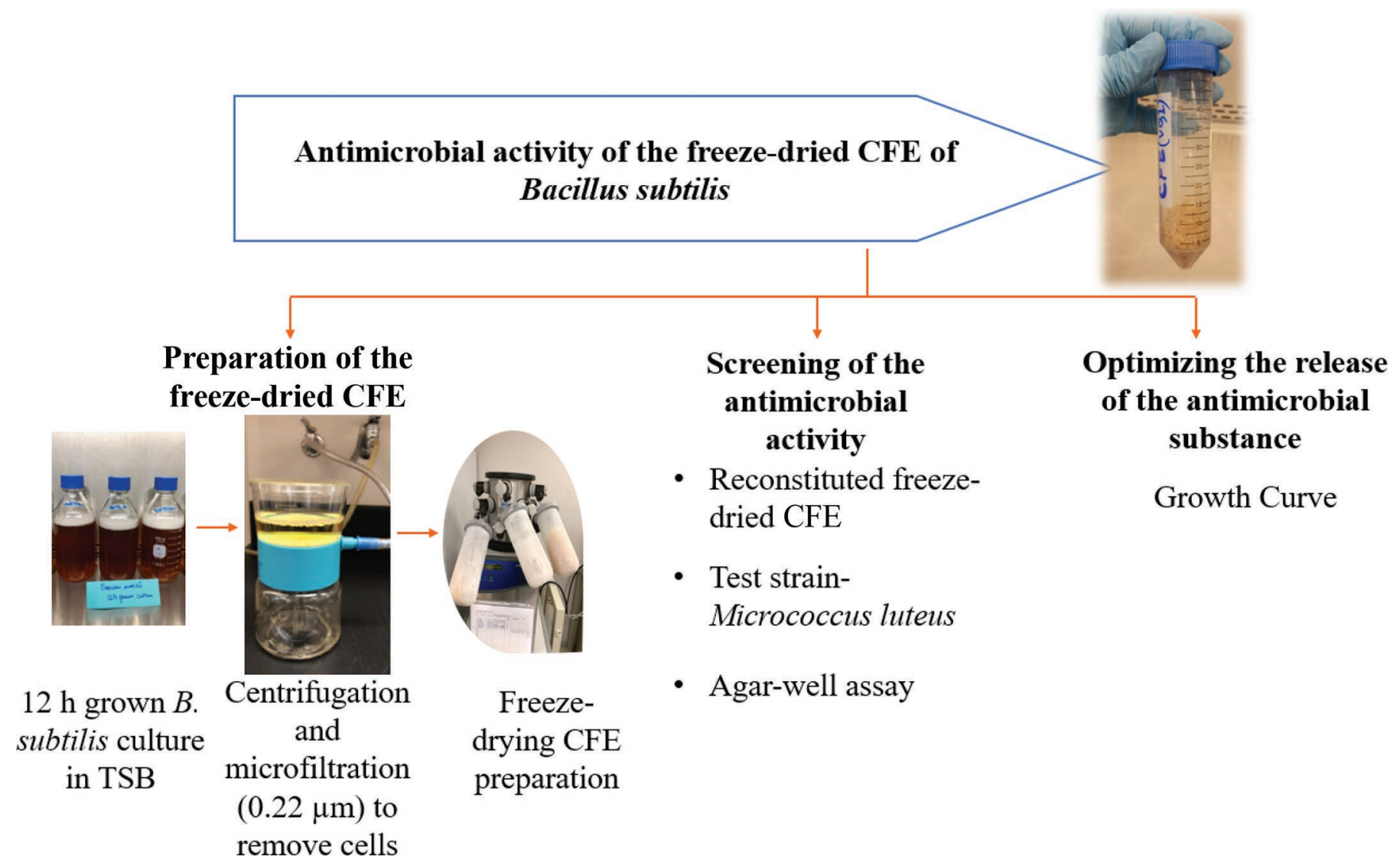

Figure 1. Antimicrobial activity of Bacillus subtilis cell-free extract (CFE).

inoculated with $500 \mu \mathrm{L}$ of the activated test culture $(M$. luteus) to achieve 7 to $8 \log _{10} \mathrm{cfu} / \mathrm{mL}$. To perform the agar-well assay, 4 wells with a diameter of $6 \mathrm{~mm}$ each were punched in the solidified medium using a sterile cork-borer, and $20 \mu \mathrm{L}$ of the reconstituted CFE was put into each of the wells. Three wells were used to put the sample (reconstituted CFE) in, and sterile HPLCgrade water was put into the fourth well as a control. The plates were incubated at $37^{\circ} \mathrm{C}$ and intermittently examined for the zones of inhibitions for up to $12 \mathrm{~h}$.

Optimizing the Release of Antimicrobial Substance by B. subtilis During Culture Incubation. The samples drawn at different stages of the growth curve of $B$. subtilis were examined to identify the incubation duration necessary for the maximum antimicrobial activity. The B. subtilis overnight growth was inoculated in TSB to achieve low inoculation levels of about $2 \log _{10} \mathrm{cfu} / \mathrm{mL}$, and the culture was incubated in a shaking incubator at $37^{\circ} \mathrm{C}$ for $72 \mathrm{~h}$. To examine the growth, the culture absorbance was measured at 600 $\mathrm{nm}$ at regular intervals (Kim et al., 2011; Sharma et al., 2018). The culture dilutions were also plated to relate the absorbance to the viable counts at a particular time interval. The microfiltered CFE were prepared at 8-,
10-, 12-, 14-, 16-, and 18-h intervals, freeze-dried, and tested for antimicrobial activity as explained earlier. The incubation period was correlated with the antimicrobial activity of CFE to ascertain the incubation duration needed for maximizing the antimicrobial activity.

\section{Characterization of the Freeze-Dried CFE}

Enzymatic Digestion to Confirm the Proteinaceous Nature of the Antimicrobial Substance. The 12-h CFE, showing maximum antimicrobial activity, was treated with different enzymes (as per their respective reaction times; Table 1) to determine the nature of the substance responsible for the inhibition of bacterial growth. To maintain similar protein concentration before digestion, the enzyme was added in a way that did not alter the volume-to-weight proportion for reconstituting CFE by adding $762 \mathrm{mg}$ of freezedried CFE in $650 \mu \mathrm{L}$ of sterile HPLC-grade water. The $\mathrm{pH}$ of the mixture and incubation temperature were adjusted to those optimal for the respective enzyme activities, followed by an agar-well assay to compare the zones of inhibition. All experiments were conducted 
Table 1. Effect of enzymatic digestion on antimicrobial activity of cell-free extract (CFE) of Bacillus subtilis

\begin{tabular}{|c|c|c|c|c|}
\hline Enzyme treatment & Enzyme diluent & $\begin{array}{c}\text { Enzyme concentration } \\
(\mathrm{mg} / \mathrm{mL})\end{array}$ & $\begin{array}{l}\text { Incubation time } \\
(\mathrm{h})\end{array}$ & $\begin{array}{l}\text { Zone of inhibition }^{1} \\
(\mathrm{~mm})\end{array}$ \\
\hline Nontreated CFE ${ }^{2}$ & - & - & - & $16.50 \pm 0.00$ \\
\hline Proteinase $\mathrm{k}$ & Double-distilled water & 10 & 6 & $6.00 \pm 0.00^{*}$ \\
\hline Trypsin & $1 \mathrm{mM} \mathrm{HCl}$ & 20 & 1 & $12.74 \pm 0.01^{*}$ \\
\hline Chymotrypsin & $1 m M \mathrm{HCl}$ & 10 & 1 & $13.50 \pm 0.10^{*}$ \\
\hline
\end{tabular}

${ }^{1}$ Zone of inhibition obtained against VQ2 (Exiguobacterium sp.) including 6-mm well size.

${ }^{2}$ Nontreated $\mathrm{CFE}=$ no enzyme treatment; only reconstituted CFE.

*Mean comparisons between nontreated CFE and each enzyme treatment (Dunnett's $t$-test) significant at the 0.05 level.

3 times, with samples tested in replicates of 3 for each trial, against one of the sensitive strains of the constitutive microflora of the 18-mo-old RO membrane (VQ2; Exiguobacteria sp.).

$C P$ Estimation and AA Profiling of the Freeze-Dried CFE. The CP content of the freezedried CFE (prepared using lyophilization) was analyzed using a protein analyzer (FLASH 1112 series EA, Thermo Finnigan, San Diego, CA), following the modified Dumas method (AACC International, 1999). In this method, approximately $100 \mathrm{mg}$ of the sample was weighed (using AT21 Comparator weighing balance, Mettler Toledo, Columbus, $\mathrm{OH}$ ) and kept in the analyzer. The protein analyzer connected to a detector that represented the nitrogen percent that was used to calculate the protein content of each sample by multiplying with 6.25 (as a conversion factor). All of the samples were analyzed in duplicates. The freeze-dried CFE was analyzed for AA profiling, and to validate the protein content, we used a protein analyzer (outsourced to Thomas P. Mawhinney, Experiment Station Chem Labs, University of Missouri, Columbia).

Stability of the Antimicrobial Activity of the Freeze-Dried CFE to Temperature and $p H$. The ability of the CFE to retain the antimicrobial activity at the commonly used sanitization temperature in a typical clean-in-place protocol was tested by exposing the reconstituted freeze-dried CFE to $24^{\circ} \mathrm{C}$ for 5 and 10 min. This time-temperature combination was similar to the sanitizer step for cleaning of RO membranes using a commercial sanitizer (Oxonia; EcoLab Inc., St. Paul, $\mathrm{MN})$. After exposing the CFE to the sanitization temperature, $20 \mu \mathrm{L}$ of the $\mathrm{CFE}$ was tested for antimicrobial activity using the agar-well assay, as described earlier in methodology against $M$. luteus.

To study the antimicrobial stability of the CFE to $\mathrm{pH}$ changes, the $\mathrm{pH}$ of the reconstituted CFE was adjusted to 3.0, 4.0, and 5.0 using a $1 N$ HCL solution. The samples were held at room temperature for 1 min (Sutyak et al., 2008) and tested for antimicrobial activity with an agar-well assay against $M$. luteus, as explained above.
MIC of the Antimicrobial Substance in the Freeze-Dried $\boldsymbol{C F E}$. The freeze-dried CFE was evaluated for the MIC, which is the lowest concentration of the antimicrobial compound required to prevent the growth of the test strain (Rota et al., 2008). To evaluate the MIC, the gradient test described by Syal et al. (2017) with slight modification was followed. Activated M. luteus, with an inoculum size of $10^{7}$ to $10^{8} \mathrm{log} \mathrm{cfu} /$ $\mathrm{mL}$, were seeded in the agar, and $20 \mu \mathrm{L}$ of the CFE with varying concentrations (10-100\%) was suspended in $6-\mathrm{mm}$ wells. The plates were incubated at $37^{\circ} \mathrm{C}$ and zones of inhibition were observed for $12 \mathrm{~h}$ at different time intervals $(6,8$, and $12 \mathrm{~h})$.

\section{Inhibition of the Constitutive Microflora of the RO Membrane Biofilm Using Freeze-Dried CFE}

The inhibition spectrum of the antimicrobial substance produced by B. subtilis was tested against the constitutive microflora of the RO membrane biofilm using the in vitro agar-well assay method (Balouiri et al., 2016). A similar experimental design was followed, as mentioned above, for screening the antimicrobial activity using the indicator organism M. luteus. After adding the reconstituted CFE in the wells, the plates were incubated at $37^{\circ} \mathrm{C}$. The zones of inhibition were observed at 6,8 , and $12 \mathrm{~h}$ of incubation.

\section{Statistical Analysis}

Each experiment was conducted 3 times with samples in replicates of 3 . Means were compared for significant differences at $P<0.05$ for the zones of inhibition using a general linear mixed model procedure of SAS (SAS Institute Inc., Cary, NC).

\section{RESULTS AND DISCUSSION}

\section{Antimicrobial Activity of the CFE of B. Subtilis and its Optimization}

To investigate the release of an antimicrobial compound by $B$. subtilis, the reconstituted freeze-dried 
CFE of B. subtilis ( $\mathrm{pH}$ 6.4) was screened against the indicator strain (M. luteus) using an agar-well assay. It is noteworthy that the zones of inhibition were observed at $6 \mathrm{~h}$ of incubation at $37^{\circ} \mathrm{C}$, revealing the antimicrobial activity of the CFE of $B$. subtilis against the test strain (Figure 2).

Optimizing the Release of the Antimicrobial Substance During the Growth of B. subtilis. The growth curve of $B$. subtilis helped in optimizing maximum zones of inhibition, as studies have demonstrated that the antimicrobial substance is produced in a growth-associated manner (Hammami et al., 2009). The results obtained demonstrated a similar trend when the freeze-dried CFE prepared at 8, 10, 12, 14, 16 , and $18 \mathrm{~h}$ were tested for their antimicrobial activity. Based on the zones of inhibition, 12-h CFE depicted maximum antimicrobial activity against $M$. luteus. The 8-h CFE did not exhibit any antimicrobial activity. A previous study also showed that an isolate of B. subtilis exhibited the maximum release of a bacteriocin after $24 \mathrm{~h}$ at $37^{\circ} \mathrm{C}$ of incubation by keeping the initial $\mathrm{pH}$ of the medium at 7.0 (Bhuvaneswari et al., 2015). Another study (Hussain, 2017) supported the maximum antimicrobial release by $B$. subtilis at neutral $\mathrm{pH}(7.0)$ and a $37^{\circ} \mathrm{C}$ incubation for $36 \mathrm{~h}$. Also, Khochamit et al. (2015) showed a drop in inhibition after a certain time of bacterial growth. The growth curve study also helped to understand the cultivation time of B. subtilis. It is noteworthy to observe that $B$. subtilis did not reach the death phase, even at $72 \mathrm{~h}$. Hammami et al., (2009) depicted similar results where B. subtilis was observed in the stationary phase at $72 \mathrm{~h}$ when the time course of B. subtilis was studied. This could be due to the sporulating nature of the culture.

Maximizing the Zone of Inhibition Size on Test Plates. The 12-h CFE optimized for maximum release of antimicrobial was selected to optimize the size of inhibition zones on agar-well assay plates. The test plates containing $20 \mu \mathrm{L}$ of reconstituted freeze-dried $\mathrm{CFE}$ in the wells were incubated at $37^{\circ} \mathrm{C}$, and zones of inhibition were measured at 6,8 and $12 \mathrm{~h}$. Means of the zones of inhibition from different time intervals $(\mathrm{h})$ were compared. The zones of inhibition obtained at 6 $\mathrm{h}$ were statistically different than those obtained at 8 and $12 \mathrm{~h}$. However, the maximum zones of inhibition were obtained at a 12-h incubation of growth plates (Table 2). It is important to note that the zones of inhibition remained constant on growth plates after 12 $\mathrm{h}$ of incubation.

\section{Characterization of the Freeze-Dried CFE}

Effect of Enzyme Digestion on Antimicrobial Activity. Bacteriocin production, a trait by bacteria to
Table 2. Maximum zones of inhibition $(18.33 \pm 0.00 \mathrm{~mm})$ were observed on agar-well assay plates at $37^{\circ} \mathrm{C}$ for $12 \mathrm{~h}$ against Micrococcus luteus

\begin{tabular}{lc}
\hline Incubation time $(\mathrm{h})$ & Zone of inhibition $^{1}(\mathrm{~mm})$ \\
\hline 12 & $18.33 \pm 0.00$ \\
8 & $17.78 \pm 0.25$ \\
6 & $15.61 \pm 1.58$ \\
\hline
\end{tabular}

${ }^{1}$ Average zones of inhibition include 6 -mm well size.

secrete proteinaceous substances to suppress the growth of competitors, could be associated with antimicrobial activity (Bucci et al., 2011). Therefore, the objective to determine the sensitivity of freeze-dried CFE to proteolytic enzymes was to establish whether the antimicrobial production in B. subtilis was proteinaceous or not. The inhibition assay revealed complete loss of activity when the CFE was treated with proteinase $\mathrm{k}$, and the activity significantly decreased by pepsin, trypsin, and chymotrypsin, establishing the proteinaceous nature of the CFE of B. subtilis (Table 1).

Studies related to loss of antimicrobial activity of $B$. subtilis have reported similar results where complete loss of activity was observed when the compound was

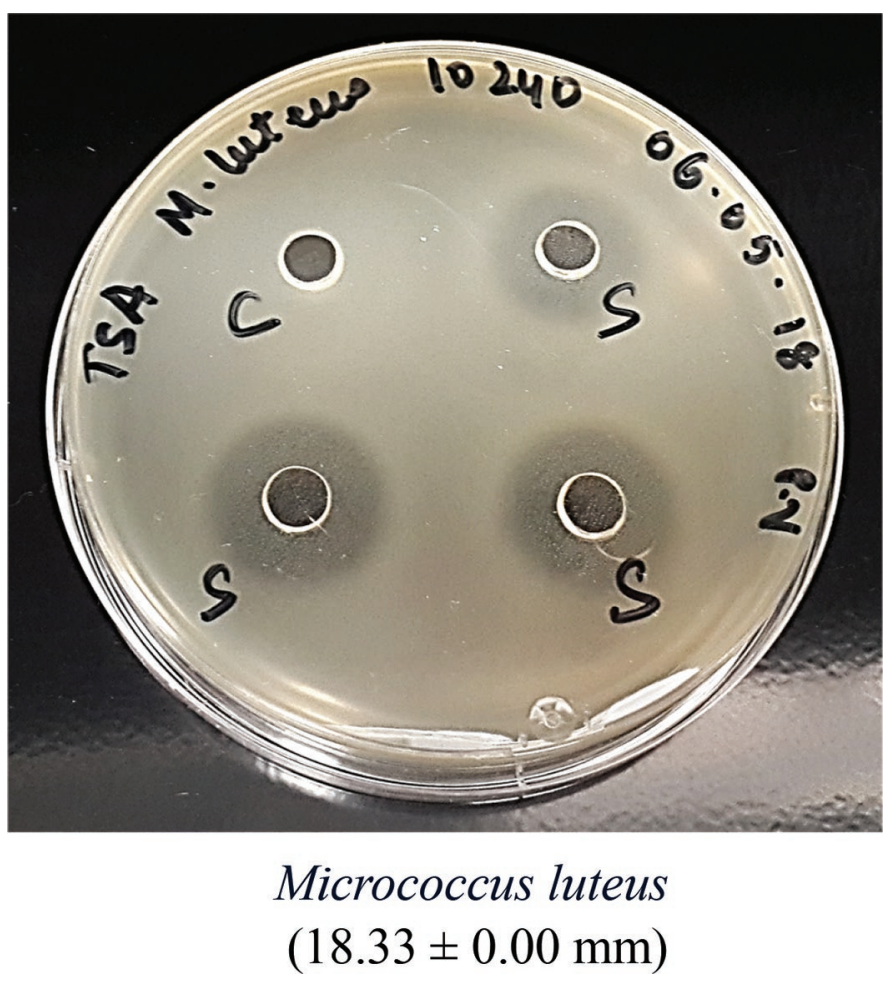

Figure 2. Clear zones of inhibition obtained by reconstituted freezedried cell-free extract (CFE) of Bacillus subtilis against Micrococcus luteus. Average zones of inhibition include $6-\mathrm{mm}$ well size. The notation "C" represents the control (HPLC-grade water); "S" represents the reconstituted CFE sample. 


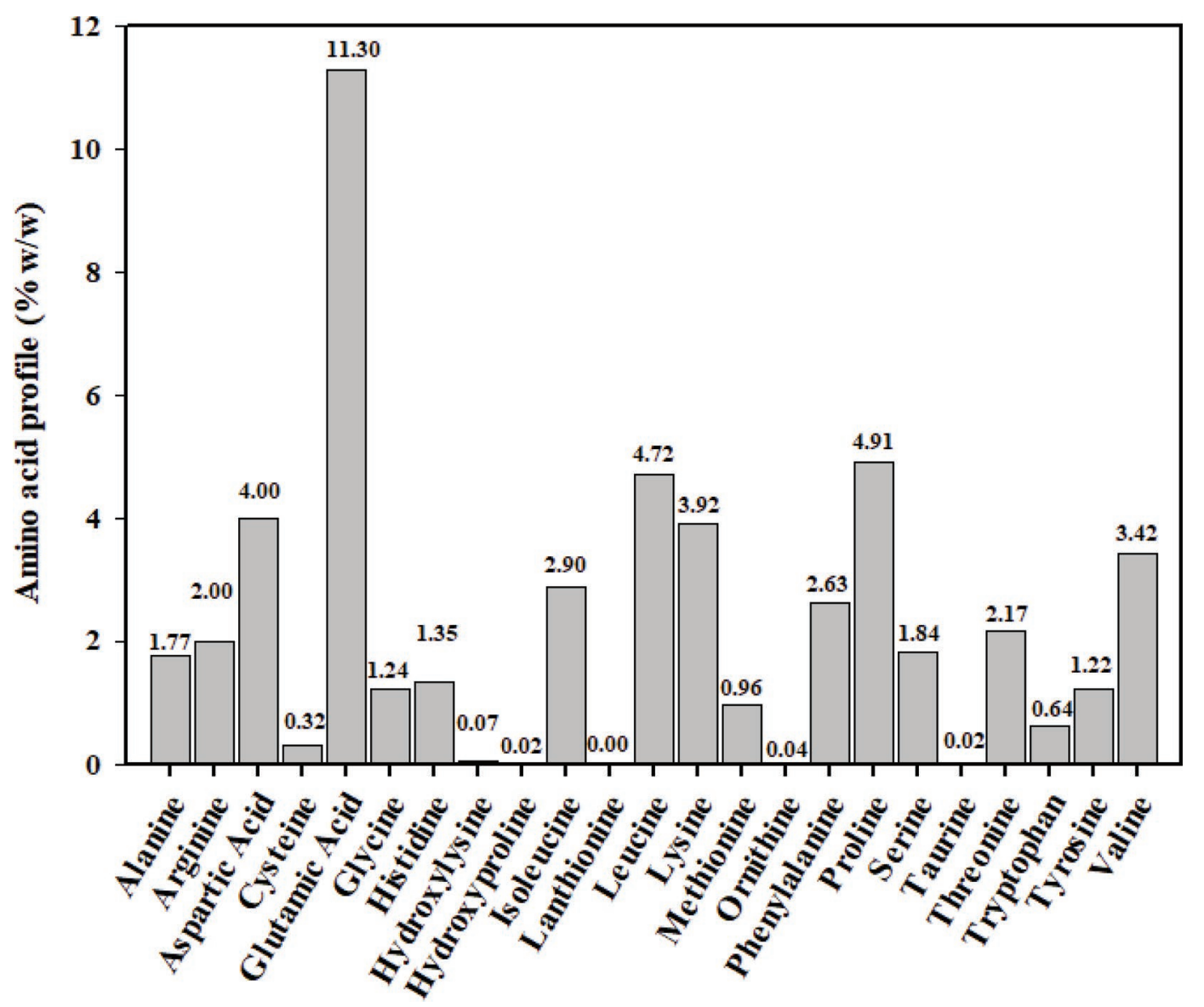

Figure 3. Amino acid profile revealed glutamic acid to be the major constituent $(11.30 \%)$ of the freeze-dried cell-free extract. Lanthionine, ornithine, and taurine were nonproteinogenic AA.

treated with proteinase $\mathrm{k}$ (Wu et al., 2013), and reduction in inhibition zones was observed on treatment with pepsin and trypsin (Teo and Tan, 2005). However, another study demonstrated complete loss of activity when treated with trypsin, but little or no effect was observed when $\mathrm{CFE}$ of $B$. subtilis was treated with proteinase $\mathrm{k}$ (Compaoré et al., 2013). Therefore, the characteristics of this antimicrobial substance are different than the previously reported compounds, which suggest that this could be a new type of compound released by $B$. subtilis responsible for inhibition of other biofilm constitutive microorganisms.

Protein Estimation. The protein analyzer determined the presence of $51 \%$ total CP content in 12 -h freeze-dried CFE prepared from B. subtilis. This was further validated by outsourcing the freeze-dried 12 -h CFE for AA profiling. This revealed the presence of $51 \% \mathrm{CP}$ in $\mathrm{CFE}$ and provided the distribution of $\mathrm{AA}$ contributing to the total CP concentration (Figure 3). Glutamic acid was found to be the major AA (11.30\%) present in the CFE. Previous studies have stated the importance of glutamic acid in exhibiting antimicrobial activity and have associated its presence with more effective bactericidal activity (Bernheimer and Avigad, 1970; Lee et al., 2014; Ajayeoba et al., 2019)

CFE Antimicrobial Stability. The thermal tolerance of the antimicrobial activity of CFE makes it suitable for a sanitizer application for membranes. Exposure to low $\mathrm{pH}$ had no apparent effect on the protein at any of the $\mathrm{pH}$ values ranging from 3.0 to 5.0. The purpose of testing the stability of the antimicrobial at sanitizer cleaning specification was to understand the usefulness of this antimicrobial to be incorporated at the sanitizer step in the regular RO membrane cleanin-place cleaning regimen.

MIC of Freeze-Dried CFE. The MIC of antimicrobial substance release by $B$. subtilis was detected using an agar-well assay against the indicator strain $M$. luteus. The purpose of evaluating the MIC was to determine the application of the CFE. Using concentrated preparation would not be a practicable approach. The results obtained revealed the MIC of reconstituted freeze-dried CFE to be as low as 10\% (Figure 4). The results thus suggested the potential to produce a bio- 

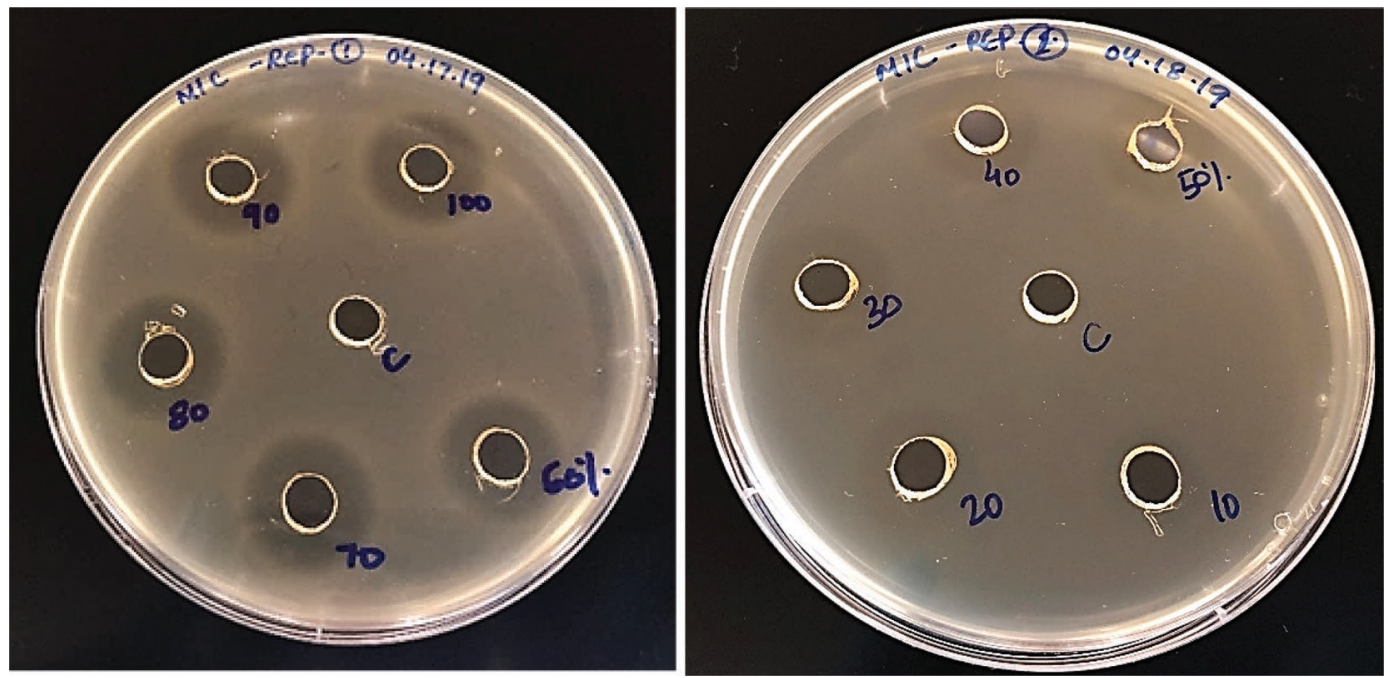

Figure 4. The MIC of reconstituted freeze-dried cell-free extract (10-100\% wt/vol). The notation "C" represents the control (HPLC-grade water).

sanitizer for industry applications, but future work is needed to assess its efficiency against a wider diversity of microorganisms, old biofilm microflora, and multispecies biofilms. Also, there is a need to study the active site responsible for antimicrobial activity and the effect of protein folding on the inhibition spectrum. Current studies in our laboratory are addressing this aspect.

\section{Inhibition Spectrum of Freeze-Dried CFE Against the Biofilm Constitutive Microflora}

The antimicrobial activity of freeze-dried CFE was tested against the constitutive microflora of the RO membrane. The agar-well assay showed that the reconstituted freeze-dried CFE of B. subtilis was active against most of the biofilm constitutive microflora isolated from the 18-mo-old RO membrane used in our study (Verma et al., 2020). Clear zones of inhibitions were observed in the agar-well assay for the constitutive microflora (Figure 5). The antimicrobial activity of $B$. subtilis thus demonstrated its ability to inhibit a variety of bacteria. A previous study (Sumi et al., 2015) also reported the broad spectrum of inhibition of $B$. subtilis against gram-positive and gram-negative bacteria. On the other hand, several other studies on bacteriocins have demonstrated their ability to inhibit

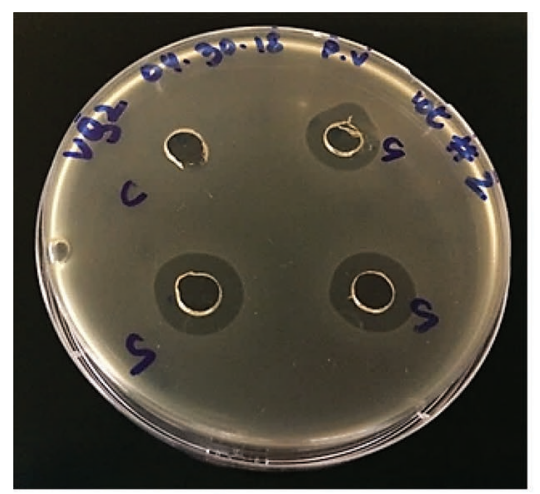

Exiguobacterium sp. $(16.50 \pm 0.00 \mathrm{~mm})$

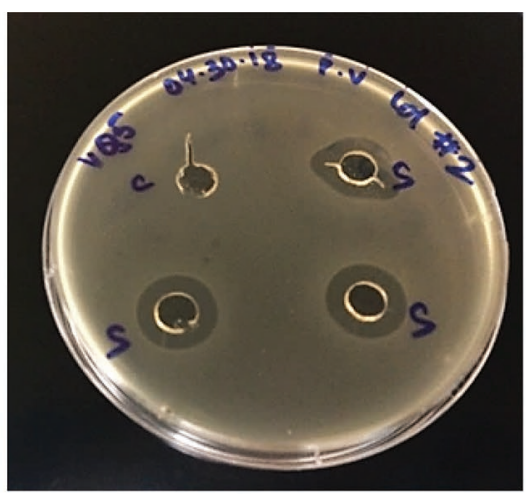

Exiguobacterium aurantiacum $(16.25 \pm 0.66 \mathrm{~mm})$

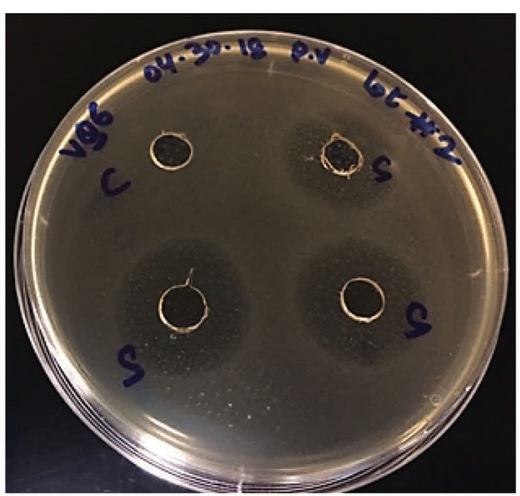

Acinetobacter radioresistens $(20.60 \pm 0.00 \mathrm{~mm})$

Figure 5. Inhibition spectrum of freeze-dried cell-free extract (CFE) of Bacillus subtilis against the constitutive microflora of the reverse osmosis membrane. Average zones of inhibition include 6-mm well size. The notation "C" represents the control (HPLC-grade water); "S" represents the reconstituted CFE sample. 
the growth of closely related species to the producing strain (Lisboa et al., 2006; Abriouel et al., 2011; Ansari et al., 2012).

Previous studies have also reported the presence of yeasts on retentate and permeate side of UF and RO membranes (Stoica et al., 2018; Vitzilaiou et al., 2019). Therefore, further studies are being conducted in our laboratory to assess the efficacy of this antimicrobial preparation against the wider diversity of microorganisms encountered in the resilient multispecies biofilms. This would provide important information related to the inhibition spectrum of this antimicrobial and its wider applicability in the dairy industry for removing biofilms.

\section{CONCLUSIONS}

To our knowledge, this is the first time that antimicrobial activity against membrane biofilm constitutive microflora by the antimicrobial substance produced by a $B$. subtilis isolate of the membrane biofilm origin has been reported. The present study revealed that the $B$. subtilis of membrane biofilm origin is a promising source of an antimicrobial substance that could be associated with its predominance within the biofilm constitutive microflora. Also, glutamic acid was found to be the major AA of the CFE preparation, has been associated with more effective bactericidal activity. Further studies are being conducted in our laboratory to study the inhibition spectrum of $\mathrm{CFE}$ of $B$. subtilis against more diverse biofilm constitutive microflora formed on used RO membranes and the effectiveness of the CFE preparation against resilient multispecies biofilms.

\section{ACKNOWLEDGMENTS}

This work was funded by the National Dairy Council (administered by Dairy Management Inc., Rosemont, IL) and supported by Agricultural Experiment Station (AES), South Dakota State University (Brookings, SD). The authors have not stated any conflicts of interest.

\section{REFERENCES}

AACC International. 1999. Approved Methods of Analysis. 11th ed. AACC International, St. Paul, MN.

Abriouel, H., C. M. A. P. Franz, N. B. Omar, and A. Galvez. 2011. Diversity and applications of Bacillus bacteriocins. FEMS Microbiol. Rev. 35:201-232. https://doi.org/10.1111/j.1574-6976.2010 $.00244 . x$.

Ajayeoba, T. A., S. Dula, and O. A. Ijabadeniyi. 2019. Properties of poly- $\gamma$-glutamic acid producing-Bacillus species isolated from ogi liquor and lemon-ogi liquor. Front. Microbiol. 10:771. https://doi .org/10.3389/fmicb.2019.00771.

Altuntas, E.G. 2013. Bacteriocins: A natural way to combat with pathogens. Pages 1005-1015 in Microbial Pathogens and Strate- gies for Combating Them: Science, Technology and Education. A. Méndez-Vilas, ed. Formatex Research Center, Badajoz, Spain.

Anand, S., A. Hassan, and M. Avadhanula. 2012. The effects of biofilms formed on whey reverse osmosis membranes on the microbial quality of the concentrated product. Int. J. Dairy Technol. 65:451455. https://doi.org/10.1111/j.1471-0307.2012.00848.x.

Anand, S., and D. Singh. 2013. Resistance of the constitutive microflora of biofilms formed on whey reverse-osmosis membranes to individual cleaning steps of a typical clean-in-place protocol. J. Dairy Sci. 96:6213-6222. https://doi.org/10.3168/jds.2013-7012.

Anand, S., D. Singh, M. Avadhanula, and S. Marka. 2014. Development and control of bacterial biofilms on dairy processing membranes. Compr. Rev. Food Sci. Food Saf. 13:18-33. https://doi .org/10.1111/1541-4337.12048.

Ansari, A., A. Aman, N. N. Siddiqui, S. Iqbal, and S. A. Ul Qader. 2012. Bacteriocin (BAC-IB17): Screening, isolation and production from Bacillus subtilis KIBGE IB-17. Pak. J. Pharm. Sci. 25:195-201.

Balakrishnan, M., R. S. Simmonds, M. Kilian, and J. R. Tagg. 2002. Different bacteriocin activities of Streptococcus mutans reflect distinct phylogenetic lineages. J. Med. Microbiol. 51:941-948. https:/ /doi.org/10.1099/0022-1317-51-11-941.

Balouiri, M., M. Sadiki, and S. K. Ibnsouda. 2016. Methods for in vitro evaluating antimicrobial activity: A review. J. Pharm. Anal. 6:71-79. https://doi.org/10.1016/j.jpha.2015.11.005.

Bernheimer, A. W., and L. S. Avigad. 1970. Nature and properties of a cytolytic agent produced by Bacillus subtilis. 61:361-369. https: //doi.org/10.1099/00221287-61-3-361.

Bhuvaneswari, S., S. Madhavan, and A. Panneerselvam. 2015. Optimization of bacteriocin production by Bacillus subtilis BMP01 isolated from Solanum trilobatum L. Int. J. Curr. Microbiol. Appl. Sci. 4:617-626.

Bucci, V., C. D. Nadell, and J. B. Xavier. 2011. The evolution of bacteriocin production in bacterial biofilms. Am. Nat. 178:E162E173. https://doi.org/10.1086/662668.

Camargo, F. A. O., B. C. Okeke, F. M. Bento, and W. T. Frankenberger. 2003. In vitro reduction of hexavalent chromium by a cell-free extract of Bacillus sp. ES 29 stimulated by $\mathrm{Cu} 2+$. Appl. Microbiol. Biotechnol. 62:569-573. https://doi.org/10.1007/s00253-003-1291 $-\mathrm{x}$.

Compaoré, C. S., D. S. Nielsen, L. I. I. Ouoba, T. S. Berner, K. F. Nielsen, H. Sawadogo-Lingani, B. Diawara, G. A. Ouédraogo, M. Jakobsen, and L. Thorsen. 2013. Co-production of surfactin and a novel bacteriocin by Bacillus subtilis ssp. subtilis $\mathrm{H} 4$ isolated from Bikalga, an African alkaline Hibiscus sabdariffa seed fermented condiment. Int. J. Food Microbiol. 162:297-307. https://doi.org/ 10.1016/j.ijfoodmicro.2013.01.013.

Gupta, S., and S. Anand. 2018. Induction of pitting corrosion on stainless steel (grades 304 and 316) used in dairy industry by biofilms of common sporeformers. Int. J. Dairy Technol. 71:519-531. https: //doi.org/10.1111/1471-0307.12444.

Hammami, I., A. Rhouma, B. Jaouadi, A. Rebai, and X. Nesme. 2009. Optimization and biochemical characterization of a bacteriocin from a newly isolated Bacillus subtilis strain 14B for biocontrol of Agrobacterium spp. strains. Lett. Appl. Microbiol. 48:253-260. https://doi.org/10.1111/j.1472-765X.2008.02524.x.

Hussain, S. N. 2017. Antagonistic effect of bacteriocin from Bacillus subtilis against food-borne pathogens. Pure Appl. Biol. 6:585-594. https://doi.org/10.19045/bspab.2017.60060.

Khochamit, N., S. Siripornadulsil, P. Sukon, and W. Siripornadulsil. 2015. Antibacterial activity and genotypic-phenotypic characteristics of bacteriocin-producing Bacillus subtilis KKU213: Potential as a probiotic strain. Microbiol. Res. 170:36-50. https://doi.org/ 10.1016/j.micres.2014.09.004.

Kim, S. H., H. S. Lee, D. S. Ryu, S. J. Choi, and D. S. Lee. 2011. Antibacterial activity of silver-nanoparticles against Staphylococcus aureus and Escherichia coli. Korean J. Microbiol. Biotechnol. 39:77-85.

Lee, N. R., T. H. Go, S. M. Lee, S. Y. Jeong, G. T. Park, C. O. Hong, and H. J. Son. 2014. In vitro evaluation of new functional properties of poly- $\gamma$-glutamic acid produced by Bacillus subtilis D7. 
Saudi J. Biol. Sci. 21:153-158. https://doi.org/10.1016/j.sjbs.2013 .09.004.

Lisboa, M. P., D. Bonatto, D. Bizani, J. A. P. Henriques, and A. Brandelli. 2006. Characterization of a bacteriocin-like substance produced by Bacillus amyloliquefaciens isolated from the Brazilian Atlantic forest. Int. Microbiol. 9:111-118. https://doi.org/10 .2436/im.v9i2.9559.

Nadell, C. D., K. Drescher, and K. R. Foster. 2016. Spatial structure, cooperation and competition in biofilms. Nat. Rev. Microbiol. 14:589-600. https://doi.org/10.1038/nrmicro.2016.84.

Oscáriz, J. C., I. Lasa, and A. G. Pisabarro. 1999. Detection and characterization of cerein 7 , a new bacteriocin produced by Bacillus cereus with a broad spectrum of activity. FEMS Microbiol. Lett. 178:337-341. https://doi.org/10.1111/j.1574-6968.1999.tb08696.x.

Rota, M. C., A. Herrera, R. M. Martínez, J. A. Sotomayor, and M. J. Jordán. 2008. Antimicrobial activity and chemical composition of Thymus vulgaris, Thymus zygis and Thymus hyemalis essential oils. Food Control 19:681-687. https://doi.org/10.1016/j.foodcont 2007.07.007.

Rotem, S., and A. Mor. 2009. Antimicrobial peptide mimics for improved therapeutic properties. Biochim. Biophys. Acta. 1788:15821592. https://doi.org/10.1016/j.bbamem.2008.10.020.

Sayem, S. M. A., A. J. M. T. Chowdhury, M. Z. Alam, and P. K. Sarker. 2018. Antibiofilm Activity of Crude Cell Free Extract from Bacillus subtilis S01 against E. coli. J. Sci. Res. 10:211-221. https: //doi.org/10.3329/jsr.v10i2.35604.

Sharma, G., S. Dang, S. Gupta, and R. Gabrani. 2018. Antibacterial activity, cytotoxicity, and the mechanism of action of bacteriocin from Bacillus subtilis GAS101. Med. Princ. Pract. 27:186-192. https://doi.org/10.1159/000487306.

Shelburne, C. E., F. Y. An, V. Dholpe, A. Ramamoorthy, D. E. Lopatin, and M. S. Lantz. 2007. The spectrum of antimicrobial activity of the bacteriocin subtilosin A. J. Antimicrob. Chemother. 59:297-300. https://doi.org/10.1093/jac/dkl495.

Stoica, I. M., E. Vitzilaiou, H. Lyng Røder, M. Burmølle, D. Thaysen, S. Knøchel, and F. van den Berg. 2018. Biofouling on ROmembranes used for water recovery in the dairy industry. J. Water Process Eng. 24:1-10. https://doi.org/10.1016/j.jwpe.2018.05.004.

Stoodley, P., K. Sauer, D. G. Davies, and J. W. Costerton. 2002. Biofilms as complex differentiated communities. Annu. Rev. Microbiol. 56:187-209. https://doi.org/10.1146/annurev.micro.56 .012302 .160705

Sumi, C. D., B. W. Yang, I. C. Yeo, and Y. T. Hahm. 2015. Antimicrobial peptides of the genus Bacillus: A new era for antibiotics. Can. J. Microbiol. 61:93-103. https://doi.org/10.1139/cjm-2014-0613.

Sutyak, K. E., R. E. Wirawan, A. A. Aroutcheva, and M. L. Chikindas. 2008. Isolation of the Bacillus subtilis antimicrobial peptide subtilosin from the dairy product-derived Bacillus amyloliquefa- ciens. J. Appl. Microbiol. 104:1067-1074. https://doi.org/10.1111/ j.1365-2672.2007.03626.x.

Syal, K., M. Mo, H. Yu, R. Iriya, W. Jing, S. Guodong, S. Wang, T. E. Grys, S. E. Haydel, and N. Tao. 2017. Current and emerging techniques for antibiotic susceptibility tests. Theranostics 7:1795-1805. https://doi.org/10.7150/thno.19217.

Tait, K., and I. W. Sutherland. 2002. Antagonistic interactions amongst bacteriocin-producing enteric bacteria in dual species biofilms. J. Appl. Microbiol. 93:345-352. https://doi.org/10.1046/ j.1365-2672.2002.01692.x.

Teo, A. Y. L., and H. M. Tan. 2005. Inhibition of Clostridium perfringens by a novel strain of Bacillus subtilis isolated from the gastrointestinal tracts of healthy chickens. Appl. Environ. Microbiol. 71:4185-4190. https://doi.org/10.1128/AEM.71.8.4185-4190.2005.

Thallinger, B., E. N. Prasetyo, G. S. Nyanhongo, and G. M. Guebitz. 2013. Antimicrobial enzymes: An emerging strategy to fight microbes and microbial biofilms. Biotechnol. J. 8:97-109. https://doi .org/10.1002/biot.201200313.

Unlu, A., T. Sar, G. Seker, A. G. Erman, E. Kalpar, and M. Y. Akbas. 2018. Biofilm formation by Staphylococcus aureus strains and their control by selected phytochemicals. Int. J. Dairy Technol. 71:637-646. https://doi.org/10.1111/1471-0307.12520.

Van Merode, A. E. J., D. C. Pothoven, H. C. Van Der Mei, H. J. Busscher, and B. P. Krom. 2007. Surface charge influences enterococcal prevalence in mixed-species biofilms. J. Appl. Microbiol. 102:1254-1260.

Verma, P., N. Singh, and S. Anand. 2020. A competitive exclusion study demonstrates the emergence of Bacillus subtilis as a predominant constitutive microorganism of a whey $\mathrm{RO}$ membrane biofilm-matrix. J. Dairy Sci. 102(Suppl. 1):187.

Vitzilaiou, E., I. M. Stoica, and S. Knøchel. 2019. Microbial biofilm communities on reverse osmosis membranes in whey water processing before and after cleaning. J. Membr. Sci. 587:117174. https:// doi.org/10.1016/j.memsci.2019.117174.

Wu, W. J., S. M. Park, and B. Y. Ahn. 2013. Isolation and characterization of an antimicrobial substance from Bacillus subtilis BY08 antagonistic to Bacillus cereus and Listeria monocytogenes. Food Sci. Biotechnol. 22:433-440. https://doi.org/10.1007/s10068-013 -0098-5.

Yannarell, S. M., G. M. Grandchamp, S. Chen, K. E. Daniels, and E. A. Shank. 2019. A Dual-Species Biofilm with Emergent Mechanical and protective properties. 18:e00670.

\section{ORCIDS}

Sanjeev Anand ๑ https://orcid.org/0000-0002-7479-9965 